\title{
Investigating the Relationship between Psychopathic Personality Traits and Decision Making Deficits in a Prison Population
}

\section{Kuin NC* and Masthoff EDM}

Penitentiairy Institution Vught, The Netherlands

\begin{abstract}
Since psychopathy poses major problems to society, it is of importance to gain more insight in this construct, which might be established by increasing knowledge of its neurocognitive underpinnings. Psychopathy may be related to failure to incorporate and learn from subtle or ambiguous feedback, which may lead to diminished awareness of potentially harmful consequences of choices. In result, this could induce increased risk-taking and decreased capability to adapt such behaviour. The aim of the present study was to investigate if a relation exists between psychopathic personality traits and risky decision making tendencies, and how this relation can be differentiated along specific symptoms of the psychopathic spectrum. Male prisoners $(N=119)$ completed a neuropsychological assessment of decision making tasks (the lowa Gambling Task [IGT] and the Wisconsin Card Sorting Task [WCST]) as well as a self-report measure for dimensional psychopathic personality traits (Psychopathic Personality Inventory - Revised [PPI-R]). In line with some of the previous literature, no significant correlations were found between measures of psychopathy on the one hand, and measures of decision making on the other hand. Other variables, such as age (with a negative correlation) and presence of a history of drug abuse did contribute significantly in the prediction of the total amount of psychopathic personality traits. Implications for interpretation of previous studies and strengths and limitations of the present study are discussed. The literature on the topic of decision making and psychopathy is now building up, but leaves inconsistent and certainly no convincing consensus. Future studies on psychopathy and neurocognition may need to shift away from traditional decision making tasks and instead focus more on experimental, 'pure' neurocognitive measures to better identify how specific cognitive pitfalls in psychopathy influence behaviour and ability to learn.
\end{abstract}

Keywords: Psychopathy; Decision making; Prisoners; Neurocognition; PPI-R

Abbreviations: DSM-IV/DSM-V: Diagnostic and Statistical Manual of Mental Disorders $4^{\text {th }} / 5^{\text {th }}$; IGT: Iowa Gambling Task; PCL-R: Psychopathy Checklist - Revised; PPI-R: Psychopathic Personality Index - Revised; RSPM: Raven Standard Progressive Matrices; TMT: Trail Making Test; WCST: Wisconsin Card Sorting Test

\section{Introduction}

For many years, the concept of psychopathy has spoken vividly to people's imagination and it received substantial attention in empirical studies $[1,2]$. Even though psychopathy is not included officially among the personality disorders in the Diagnostic and statistical manual of mental disorders, both $4^{\text {th }}$ and $5^{\text {th }}$ edition (DSM-IV-TR; DSM5) and International statistical classification of diseases and related health problems, tenth revision (ICD-10), it is widely accepted as a real and potentially detrimental phenomenon [3,4]. The definition of psychopathy by Hare [5] is applied most. According to this definition, psychopathy is portrayed by a constellation of affective, interpersonal and behavioural characteristics, such as egocentricity, impulsivity, lack of remorse and empathy, shallow affect, manipulativeness and persistent violation of social norms [4]. Hare [5] divides these traits across two factors; factor one refers to remorseless, cold personality traits (callous unemotional traits), while factor two refers to aspects of an antisocial and impulsive lifestyle. Despite the global use of this concept, there are still different views on the exact nature of the core features of psychopathy, which could be clarified by gaining more insight in its neurocognitive underpinnings. Indeed, growing neuroscientific evidence points to specific neurocognitive deficits in people suffering from psychopathy. For example, problems have been found in people with psychopathy with respect to focussing attention to emotional cues, either leading to low distractability by these cues or to reduced facilitation by emotional helpful cues [6,7]. Furthermore, studies have shown different reactions for psychopaths versus nonpsychopaths in the integrity of the neurocognitive processes driving attentional allocation [8], and especially in top-down incorporation of contextual information during attentional processing [9]. In addition, neuroimaging studies have shown that psychopathic traits are related to lower activation in affect-processing brain areas, such as the amygdala, during emotion eliciting tasks, and to increased activation in frontal brain regions that are related to cognitive control during tasks involving decision making and reward processing [10]. Gaining more knowledge on the specific nature of these neurocognitive deficits in relation to different psychopathy-endophenotypes, such as high scorers on factor one traits and high scorers on factor two traits, may be especially useful to give rise to a new line of treatments [11], for example based on techniques of cognitive remediation [12].

One aspect of neurocognition that has often been assessed in relation to psychopathy, is decision making strategy, especially in ambiguous circumstances. Feedback received in daily life after the

*Corresponding author: Niki Kuin C, Penitentiairy Institution Vught, Postbus 10055, $5260 \mathrm{DH}$ Vught, The Netherlands, Tel: 0031-8807-44000; E-mail: n.kuin@dji.minjus.nl

Received January 14, 2016; Accepted February 24, 2016; Published March 10 2016

Citation: Kuin NC, Masthoff EDM (2016) Investigating the Relationship between Psychopathic Personality Traits and Decision Making Deficits in a Prison Population. J Foren Psy 1: 104. doi: 10.4172/2475-319X.1000104

Copyright: ( 2016 Kuin NC, et al. This is an open-access article distributed under the terms of the Creative Commons Attribution License, which permits unrestricted use, distribution, and reproduction in any medium, provided the original author and source are credited. 
making of decisions is often either absent, subtle (through nonverbal social signals, for example) or ambiguous (meaning that one decision may lead to both positive and negative outcomes). These characteristics may be mimicked in decision making tasks, for example by providing concurrent winnings and losses in result of a choice. Psychopathy may be related to an impaired ability to incorporate and learn from such subtle or ambiguous feedback pointing to potentially harmful consequences of choices [13]. This could possibly be due to a lessened capability in individuals with psychopathy to experience negative affect in connection to awareness of negative behavioural outcomes [14], which in turn could lead to more risk taking. Many studies have been conducted to investigate if psychopathic traits are related to a disadvantageous, risky decision making style during simulated gambling tasks and reduced learning on such tasks after (ambiguous) feedback. The results of several studies at least partly support this hypothesis in normal (young) adult samples [15-19], as well as in clinical and forensic samples [20-23] and children [24,25]. Nonetheless, other studies showed no [26,27] or even a negative correlation [28]. Interesting in this regard is that these latter studies were all conducted in criminal samples, where psychopathic personality traits may be eminently pronounced and destructive. In these groups especially, better understanding of neurocognitive underpinnings of psychopathy is essential, in order to be able to lessen the social burden of psychopathy through reduction of offense recidivism.

Given the heterogeneity and complexity of the psychopathy construct, it has been suggested that studies should further distinguish between subtypes or specific traits of psychopathy in relation to decision making, so the aforementioned scientific inconsistencies could be better explained [28]. For example, some researchers reason that risky decision making would be primarily related to aspects of an antisocial and impulsive lifestyle [17,29] (factor two of the Hare construct). Also, a specific relation between risky decision making and callous unemotional traits (factor one of the Hare construct) has been suggested [30], presumably due to amygdala malfunctioning [7,31,32]. Only two of the studies that differentiated between these two subtypes in forensic samples indeed showed a larger tendency for risky decision making in relation to antisocial lifestyle aspects of psychopathy [21,22]. However, the two studies with the largest samples $(N=49$ and $N=157)$ found no such relation [26,27], and results of another relative large study $(N=$ 49) showed that the antisocial lifestyle component was related to better decision making [28]. These results seem to indicate that differentiating between psychopathy subtypes doesn't help to clarify if and how psychopathic traits are related to increased risk taking during decision making. However, none of the studies differentiated psychopathic traits further than on the basic level of either aspects of impulsivity and antisocial lifestyle or callous unemotional traits. Therefore, we aim to repeat earlier studies in a large sample of male detainees, and assess if in this population psychopathic personality traits, disentangled on a more detailed level, are positively correlated to the tendency to make risky decisions on a frequently applied simulated gambling task. Based on the existing literature, it is a priori hypothesized that psychopathic personality traits are not correlated to risk-taking behaviour during decision making.

\section{Material and Methods}

\section{Setting and procedure}

All participants signed informed consent after receiving both oral and written information about the study. Participants were recruited from different types of regimes in a large prison setting in the Netherlands (Penitentiairy Institution Vught). Participation took place on a voluntary basis after being approached by research assistants. Collection of the complete data for this study took up one or two meetings after a first information session, depending on available time in the daily prison program and the attention span of the participant. After informed consent was signed, research assistants (master students psychology) administered a short semi-structured interview to gather general personal data, such as age, history of substance abuse, and educational level. Subsequently, neuropsychological tasks were administered, alternated with a self-report questionnaire to assess psychopathic personality traits. Neuropsychological testing was mainly directed towards measuring aspects of risky decision making and setshifting, but also measures of intelligence and attention were included, to be able to correct for these aspects in the statistical analyses. If appreciated by the participants, they were provided with feedback on their individual test results in a final meeting. No incentives were provided.

Testing was performed by a research assistant in offices nearby the ward of the participants. In some exceptional cases, due to necessary security precautions, staff members were present as well. These staff members took no part in test-administration and received no insight in individual test performance.

Lastly, criminal records were searched by test-assistants to be able to provide insight in past criminal behaviour and demographics. The study was approved by the scientific department of the Dutch Ministry of Justice and Security with respect to procedural and ethical aspects.

\section{Materials}

\section{Psychopathy-assessment}

Psychopathic Personality Inventory revised (PPI-R): The PPI-R [6] is an often applied self-report instrument to assess psychopathic personality traits. It contains 154 items which are scored on a fourpoint likert scale. This instrument was selected for the present study because of its ease to administer and because it provides insight in multiple, specific psychopathic personality characteristics. In addition to a score on the Total Psychopathy index, scores are provided on eight content scales (i.e., Machiavellian Egocentricity, Rebellious Nonconfirmity, Blame Externalization, Carefree Nonplanfulness, Social Influence, Fearlessness, Stress Immunity, and Coldheartedness) as well as on two validity scales (Virtuous Responding, and Deviant Responding). Furthermore, two higher order factors can be derived (Fearless Dominance, and Self-Centered Impulsivity), which reflect the two factors of the psychopathy construct as defined by Hare, with the content scale 'Coldheartedness' regarded as a separate third factor. Construct validity of these factor scales has been established in criminal samples [33]. However, recent evidence only supports construct validity for the second higher order PPI-factor (Self-centered Impulsivity) but not for the Fearless Dominance scale [34].

\section{Neuropsychological measures}

Iowa gambling task (IGT): The IGT [13] is regarded as an adequate measure of intuitive decision making in ambiguous and risky circumstances. Because it contains ambiguous reinforcers, it is supposed to resemble daily life decision making closely. In the present study, the IGT was assessed with a standard version of a computer task in which participants were confronted with four packs of cards. They were instructed to select one card at a time with the consequence of winning or losing fictitious money. After each card drawing, a fictitious reward was given. Sometimes this was accompanied by a loss as well 
(meaning that one could win and lose money at the same time). Two decks were advantageous decks which gave small rewards and small losses. Two decks were disadvantageous: these gave high rewards and high losses. Participants were only informed that some decks were better than others. Each participant completed 100 deck draws, leading to a total score and five consecutive 'block' scores of 20 draws each. Especially the last two blocks (representing the final 40 draws) need to be considered with respect to risky decision making [35], while the first three blocks are characteristic for decision making under ambiguity [36].

Wisconsin card sorting task (WCST): The computerised version of the WCST [37] was included in the present study as a measure of more classic executive functions (where decision making depends on reasoning primarily, instead of gambling). In contrast to the IGT, performance on the WCST relies less on intuition, but more on logical thinking and deliberative decision making. The WCST is widely accepted and applied, both for clinical diagnostic and research purposes [38]. Participants were instructed to organize different pictures in categories, but received no insight in the underlying organizing principles prior to the test. Only feedback was provided after each sorting attempt as being 'good' or 'false'. When the right sorting principle was applied consequently and repeatedly, the rule changed without notification, requiring a flexible and analytical response.

Trail making test (TMT): The TMT is a neuropsychological task, designed to assess (divided) attention [39]. It requires speed and good visual scanning skills, as well as sequencing [38]. In condition A, participants were instructed to draw lines between numbers as fast as possible (1-2-3-4-...), while in condition $B$, the instruction was to draw lines between numbers and letters and switch between those (1-A-2-B3-C-...). Time to complete these tasks is regarded as a good indicator for processing speed (condition A) and divided attention (condition B in contrast to condition A).

Raven standard progressive matrices (RSPM): The RSPM is a non-verbal intelligence test [40], where abstract reasoning is essential. Participants were instructed to fill in missing parts in a pattern, choosing from a set of options. The test was selected on basis of its completion time and applicability for people, who aren't raised with the Dutch language. Dutch norms were applied [38] to provide percentile scores, which were next converted into IQ-estimates.

\section{Participants}

All participants were adult males (18 years and older), who were currently incarcerated. Inclusion took place when participants were stable enough to participate (e.g. not suffering from a psychotic, manic or major depressive episode during at least three months prior to testing, according to their self-report and confirmation from their psychologists). Illiteracy was an exclusion criterion, because of the use of questionnaires.

Out of the 157 men who initially signed up for the study, a total number of 123 participants completed the study. Exclusion details are provided in Figure 1. These participants resided for the larger part in regular prison wards $(n=97)$, and to a lesser extent in specialized areas of the prison, such as a penitentiairy psychiatric centre $(n=19)$, a ward for habitual offenders, $(n=4)$, and a segregated ward for prisoners with severe violent behaviour $(n=3)$. The larger part of the participants was native to the Netherlands $(n=88)$, while the rest was born in other European countries $(n=7)$, Northern America $(n=1)$, Southern America $(n=14)$, Africa $(n=5)$, or Asia $(n=2)$.

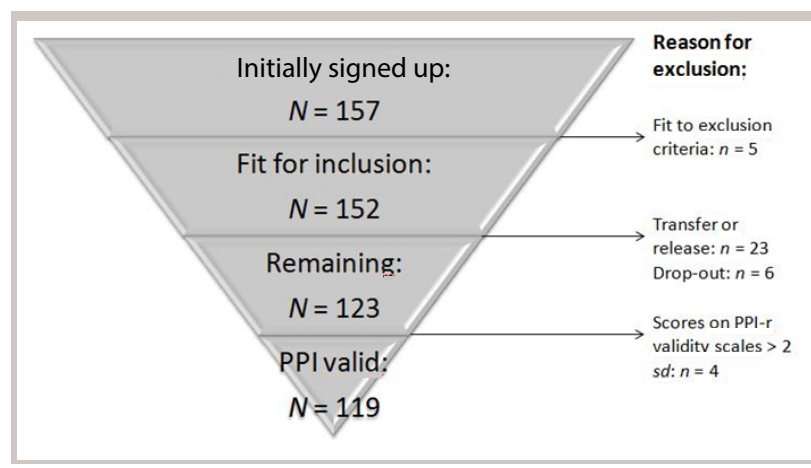

Figure 1: Flowchart of participant inclusion and exclusion.

To ensure the validity of the data, all participants, who scored more than two standard deviations above the mean on the validity scales of the PPI-R (Virtuous Responding, $M=31.60, S D=5.94$, and Deviant Responding, $M=14.25, S D=3.42$ ), were excluded from the statistical analyses, in line with the procedure from Miranda et al. [41]. This led to exclusion of four participants, leaving a total sample size of 119. In Table 1 descriptive data are provided for the sample under study.

\section{Statistical procedure}

Before conducting any statistical analyses, a check was performed to determine if there was no violation of the assumptions of normality, linearity and homoscedasticity. Bearing the large sample size in mind, the shape of the distributions was examined visually to assess normality, using histograms and Q-Q plots. Linearity and homoscedasticity were checked by means of plots of standardized residuals against predicted values.

Next, correlations were calculated between all predictors and dependent variables on the one hand and potential mediating variables on the other hand, the latter being: age, intelligence (IQ-estimate RSPM), educational level, attention (based on seconds to complete TMT-A, TMT-B, and TMT-B/A), and history of drug or alcohol abuse. If any correlations were significant, these potentially mediating variables were included as predictor in the regression analysis. To investigate if decision making variables could statistically significant predict outcome on the PPI-R total score, a multiple linear regression analysis was conducted with forced entry. All covariates were inserted in Step 1, the IGT variables in Step 2, and the WCST variables in Step 3. Missing values in the regression analysis were replaced by the mean $(n=4)$.

Since the validity of the two second order factors of the PPI-R may be questionable, a partial confirmatory factor analysis was wielded [42] with a fixed number of three factors (which should resemble the three higher order factors: Fearless Dominance, Self-Centered Impulsivity and Coldheartedness), using KMO and Bartlett's test of sphericity and direct oblimin oblique rotation.

Parametric and non-parametric correlations were calculated between measures of decision making and measures of psychopathy based on either Pearson's $r$ (in case of normal distribution of the data) or Spearman's $\rho$ (when one of the variables was not normally distributed). Only for significant correlations multiple linear regression analyses were conducted, using the forced entry of variables. Variables of decision making were entered as predictors (after the covariates) in the analyses and the applicable personality measures as dependent variable. The level of significance was set at an alpha of $\leq 0.01$, because 


\begin{tabular}{|c|c|c|c|}
\hline Measure & $\mathbf{N}$ & Mean (M) (range) & Standard Deviation (SD) \\
\hline Age & 119 & $35.95(18-74)$ & 11.24 \\
\hline Educational level': & 119 & $3.28(1-6)$ & 1.03 \\
\hline IQ (RSPM) & 119 & $85.52(70-124)$ & 11.52 \\
\hline Number of convictions & & $21.51(1-91)$ & 20.71 \\
\hline Number of previous violent convictions & & $4.03(0-79)$ & 7.78 \\
\hline Number of previous non-violent convictions & & $16.52(0-82)$ & 18.39 \\
\hline \multicolumn{4}{|l|}{ Current offense: } \\
\hline - traffic offense/breach of conduct & 8 & - & - \\
\hline - drug offense & 16 & - & - \\
\hline - burglary & 29 & - & - \\
\hline - assault and battery & 24 & - & - \\
\hline - aggravated assault & 4 & - & - \\
\hline - sex crimes & 4 & - & - \\
\hline - sex crimes with minor victims & 9 & - & - \\
\hline - arson & 1 & - & - \\
\hline - (attempt) manslaughter & 7 & - & - \\
\hline - (attempt) murder & 17 & - & - \\
\hline
\end{tabular}

Note: ${ }^{1}$ Educational level was based on mean scores on the classification system of Verhage [58] in Dutch education with 6 levels of education: (1) not graduated from primary school, (2) only graduated from primary school, (3) vocational education, (4) secondary vocational education, (5) higher vocational education, (6) academic education.

Table 1: Descriptive data of the study sample.

multiple analyses have been run.

\section{Results}

Assumptions of linearity and homoscedastity were not violated. However, most of the decision making variables were not normally distributed (especially scores on the WCST, probably due to a ceiling effect on that test), in contrast to the personality and other variables where the assumption of a normal distribution was not violated.

Can psychopathic traits in general be statistically significantly predicted by scores on decision making tasks?

In the first regression analysis with the total score on the PPI-R as dependent variable, no outliers needed to be excluded (none exceeded $>3 S D$, and only five out of 119 exceeded $>2 S D$ ). Assumptions of normal distribution, homoscedasticity and linearity of the residuals were not violated. There was slight multicollinearity between predictors, but in general VIF and tolerance scores were acceptable (for covariates VIF $\leq 1.24$, tolerance $\geq 0.81$; for IGT variables VIF $\leq 3.28$, tolerance $\geq 0.31$; for WCST variables VIF $\leq 7.51$, tolerance $\geq 0.13$ ). The assumption of independent errors was tenable (Durbin Watson $=2.04$ ). The results of this regression analysis are shown in Table 2 . As can be seen, only the variables, that were corrected for (age and history of drug or alcohol abuse), contributed significantly to the variance of the regression model (no TMT variables were included, because of lack of any relevant significant correlations to the dependent variables). Together, they explained $16.7 \%$ of the variance of PPI-R total scores. None of the IGT-scores (scores on block 4 and 5 and total NET score) contributed to the explained variance of the model. Neither did any of the WCST scores, that were inserted as Step 3 in the model (being number of perseverative and non-perseverative errors and number of completed categories). These are left out of Table 2.

Can scores on specific psychopathic characteristics significantly predict scores on decision making tasks?

Results of the partial confirmatory factor analysis, to test the fit of the higher order factor structure of the PPI-R, showed best though still insufficient fit for a three factor model $(N F I=0.96$; $T L I=0.91$;

\begin{tabular}{|c|c|c|c|c|}
\hline & B [95\% confidence interval] & SE & $\beta$ & $p(\alpha=0.05)$ \\
\hline \multicolumn{5}{|c|}{ Step 1} \\
\hline Constant & $410.59[361.44,459.75]$ & 24.81 & & $p<0.001$ \\
\hline Age & $-0.60[-1.13,-0.06]$ & 0.27 & -0.19 & $p<0.05$ \\
\hline IQ-estimate (RSPM) & $-0.44[-1.01,0.12]$ & 0.29 & -0.14 & $p=0.13$ \\
\hline Educational level & $-5.00[-11.37,1.46]$ & 3.24 & -0.15 & $p=0.13$ \\
\hline History of drug abuse & $16.80[3.05,30.55]$ & 6.94 & 0.21 & $p<0.05$ \\
\hline \multicolumn{5}{|c|}{ Step 2} \\
\hline Constant & $413.06[362.43,463.68]$ & 25.55 & & $p<0.001$ \\
\hline Age & $-0.61[-1.15,-0.07]$ & 0.27 & -0.2 & $p<0.05$ \\
\hline IQ-estimate (RSPM) & $-0.45[-1.03,0.14]$ & 0.3 & -0.15 & $p=0.13$ \\
\hline Educational level & $-5.08[-11.50,1.34]$ & 3.24 & -0.15 & $p=0.12$ \\
\hline History of drug abuse & $16.46[2.68,30.25]$ & 6.96 & 0.21 & $p<0.05$ \\
\hline IGT Score Block 4 & $-0.64[-1.60,0.32]$ & 0.49 & -0.18 & $p=0.19$ \\
\hline IGT Score Block 5 & $-0.34[-1.16,0.49]$ & 0.42 & -0.1 & $p=0.42$ \\
\hline IGT Total NET Score & $0.23[-0.10,0.56]$ & 0.17 & 0.21 & $p=0.18$ \\
\hline \multicolumn{5}{|c|}{ Note: $\mathrm{R}^{2}=0.167$ for Step $1 ; \Delta R^{2}=0.022$ for Step $2(p s=0.389)$} \\
\hline
\end{tabular}

Table 2: Linear model predictors of PPI-R total score.

$C F I=0.82 ; R M S E A=0.05)$. Although one of the three found factors did represent the Coldheartedness scale as a separate factor, the two other factors found in the factor analysis did not consist of the same content scales as the Fearless Dominance and Self Centered Impulsivity factors should contain (the content scales Fearlessness and Carefree Nonplanfulness loaded stronger on other factors than on the ones that they were supposed to). Therefore, these two higher order factors (Fearless Dominance and Self Centered Impulsivity) were left out of any further analyses.

Before conducting a regression analysis, correlations between measures of decision making (Mean IGT scores on Block 4 and 5 and NET Total score, WCST perseverative and non-perseverative errors, completed categories WCST) and measures each of the eight content scales of the PPI-R were calculated (for IGT scores Pearson's $r$ was calculated and for WCST scores Spearmans $\rho$ ). The correlation between IGT Block 4 score and PPI-R Social Influence was significant $(r=-0.24, p=0.010)$. Correlations approaching significance were found between WCST non-perseverative errors and PPI-R Stress Immunity 
$(\rho=0.19, p=0.036)$, WCST completed categories and PPI-R Carefree Nonplanfulness $(\rho=0.21, p=0.024)$, WCST completed categories and PPI-R Fearlessness ( $\rho=0.19, p=0.045)$, and WCST perseverative errors and PPI-R Social Influence $(\rho=0.17, p=0.064)$.

After correcting for potentially mediating variables such as age, IQ-estimate on the RSPM, educational level and history of drug abuse in the regression analyses, the correlation between WCST completed categories and PPI-R Carefree Nonplanfulness became significant $(b=$ $1.38, S E=0.44, \beta=0.32, p=0.002)$, while the correlation between IGT Block 4 score and PPI-R Social Influence only approached significance $(b=-0.20, S E=0.08, \beta=-0.22, p=0.016)$.

\section{Discussion}

The aim of the present study was to investigate if there was a positive correlation between specific types of psychopathic personality traits, as determined with the PPI-R, and risky decision making in male prisoners. Although we were not able to provide valid scores for a higher factor model of the three main dimensions of the PPI-R (Fearless Dominance, Self-Centered Impulsivity and Coldheartedness), we did investigate the relation between risky decision making and specific psychopathy traits on the eight content scales of the PPI-R. We did not find convincing evidence for such a relation to general psychopathy or to any specific psychopathic trait whatsoever. This was the case both when assessing risky decision making with the IGT and when assessing set-shifting with the WCST. If any correlation seemed present, it disappeared largely when correcting for other variables, of which age and history of drug abuse had the most pronounced contribution.

The results of the present study with respect to risky decision making are in line with those of some earlier studies with criminal samples [2628]. The cumulation of these results gives strong evidence that risky decision making is not related to any specific psychopathic personality trait, at least in offenders. This suggests that the brain-behavior relations in psychopathy, for example related to malfunctioning of the amygdala and ventromedial prefrontal regions, are not as clear-cut as may have been previously hypothesized [13]. This could, for example, be explained because other, unaffected neural pathways are able to compensate for amygdala deficits and thus enable psychopaths to show intact decision making on tasks such as the IGT through other, intact cognitive processes [7]. Performance on the IGT depends on multiple cognitive processes, where both emotional and attention functions seem to interplay, and which are difficult to entangle based on the traditional scoring that we applied. Therefore, we cannot verify this assumption of neurocognitive compensation. Other researchers have made attempts to develop other scoring models for the IGT, such as the 'Expectancy Valence Model' [43] or the 'PVL-model' [44], which future studies could apply to unravel cognitive processes during completion of the IGT. Imaging studies could show if brain activation patterns during decision making differ between psychopaths and non-psychopaths. In fact, one study has indeed shown diminished neural activation in parts of the anterior cingulate cortex and prefrontal cortex for emotional hypo-reactive offenders (thus high on callous unemotional traits), when compared to normal controls, during completion of a gambling task [30]. No increased activation in other parts of the brain were recorded, however.

Another explanation for the absence of a relation between risky decision making and psychopathic traits, especially within criminal populations, may be found in general antisocial characteristics of these groups. It has been suggested that not psychopathy, but impulsive antisociality in general, may be related to risky decision making
[41]. If this were true, this could imply that on average offenders all show decision making problems. Some studies did indeed show that offenders performed generally worse on the IGT than normal controls $[45,46]$. Adding a normal control group to a design with offenders could help to verify this problem. Furthermore, measuring (impulsive) antisocial behaviour instead of psychopathic personality could lead to a broader insight in other factors that are related to poor decision making in forensic populations. In fact, it has been found that behavioural measures of antisocial behaviour (such as aggression and criminal behaviour) show stronger relations to neuropsychological executive tasks than measures of antisocial personality [47] and there are also findings that risky decision making is related to aggression [48].

Notwithstanding the foregoing, questions remain why some previous studies did find that the amount of psychopathic traits was positively correlated to risk taking while making decisions [15-18,2023]. One explanation might be that previous studies may have showed invalid or biased results, for example because of small sample sizes or because of not correcting for factors such as age and (history of) drug abuse. In fact, only one study mentioned having matched groups for history of drug abuse [20], while only four matched or corrected for age $[17,20,22,23]$. Our finding that the latter factors are associated with the tendency for risky decision making is in line with previous studies. For example, risk taking seems to vary across the lifespan [49-51] and substance abuse has often been linked to decision making impairments [52-54].

Although our study was strong with respect to its correction for such covariates, there are still some critical notes to be placed. For example, validity of the PPI-R may be disputed. Although the PPI-R is applied on a large scale, there are studies that show good applicability for this test in the normal population, but poor validity in forensic populations [14]. It could be that this issue with the PPI-R validity might explain the difference in outcome of our study in comparison to similar studies in normal populations. Furthermore, the PPI-R as a dimensional instrument does not provide a cut-off point to differentiate between actual clinical psychopathy (who score above a cut-off score), and evident non psychopaths, or people who score just below the threshold with so-called subclinical psychopathic traits. Therefore, based on our data we cannot say with certainty how many 'true psychopaths' were included in our all-volunteer sample, and, as such, if delinquents suffering from clinical psychopathy show decision making deficits in contrast to non-psychopaths. However, similar studies in criminal populations using the 'Psychopathy Checklist Revised' (PCL-R), which is generally regarded as the golden standard instrument to distinguish psychopaths from non-psychopaths, or the PCL's short version [55], showed results similar to our study [26-28].

One last interesting finding in our study was that the number of completed categories on the WCST showed a small but significantly positive correlation to the PPI-R subscale Carefree Nonplanfulness, which suggests that participants who describe themselves as being less organized, actually perform better on a measure of executive functioning. Although it is generally accepted from previous studies that psychopathy in general and performance on set-shifting tasks on the WCST are not related [7], this remains a curious finding. A potential explanation could lie in faking good behaviour or in poor self-insight, which would suggest that scores on the PPI Carefree Nonplanfulness scale should be interpreted with caution. However, a meta-analytic review on faking good behaviour, did not demonstrate a consistent relation between faking good response styles and self-report measures of psychopathy, including the PPI-R [56]. Also, in an empirical study 
Citation: Kuin NC, Masthoff EDM (2016) Investigating the Relationship between Psychopathic Personality Traits and Decision Making Deficits in a Prison Population. J Foren Psy 1: 104. doi: 10.4172/2475-319X.1000104

Page 6 of 7

[57], no relation was found between poor self-insight and psychopathic personality traits. Because of the foregoing, the above suggested possible explanation for the found correlation is not plausible. Therefore, future studies should point out whether or not this was a coincidental finding [58].

\section{Conclusion}

No relation whatsoever was found between decision making and aspects of psychopathy in a sample of male prisoners. These findings correspond with those of some previous studies, but contradict those of others. Potential explanations for these differences have been discussed, including some limitations of our study. Given the strength of our study, coming from a relatively large sample size and good statistical correction for distorting variables, we feel that the attribution of this study to the field of neuroscientific research in relation to psychopathy is relevant. Since literature on the topic of decision making and psychopathy is building up and leaves inconsistent and certainly no convincing results, future studies on psychopathy and neurocognition may need to shift away from traditional decision making tasks and instead focus more on experimental, 'pure' neurocognitive measures to better identify how specific cognitive pitfalls in psychopathy influence behaviour and ability to learn. 'Pure' neurocognitive measures are measures where performance is dependent on one solitary cognitive function instead of concurrent different cognitive processes, which is the case with instruments such as the IGT and WCST. That could help clarify better which exact cognitive mechanisms are at work.

\section{Acknowledgements}

No funding was received for this study. We would like to thank M Kramer, S Setorg, M Rutten, P Fasel, A van Lieshout and J Oomkens for their help with the data-collection.

\section{References}

1. Cummings MA (2015) The neurobiology of psychopathy: recent developments and new directions in research and treatment. CNS Spectr 20: 200-206.

2. Wong SC, Olver ME (2015) Risk reduction treatment of psychopathy and applications to mentally disordered offenders. CNS Spectr 20: 303-310.

3. International Statistical Classification of Diseases and Related Health Problems, Tenth Revision.

4. Hare RD, Hart SD, Harpur TJ (1991) Psychopathy and the DSM-IV criteria for antisocial personality disorder. J Abnorm Psychol 100: 391-398.

5. Hare RD (1980) A research scale for the assessment of psychopathy in criminal populations. Personality and Individual Differences 1: 111-119.

6. Lilienfeld SO, M WidowsProfessional Manual for the Psychopathic Personality Inventory-Revised (PPI-R). 2005, Lutz, FL: Psychological Assessment Resources.

7. Blair RJ, Mitchell DG (2009) Psychopathy, attention and emotion. Psychol Med 39: $543-555$

8. Brazil IA, Verkes RJ, Brouns BH, Buitelaar JK, Bulten BH, et al. (2012) Differentiating psychopathy from general antisociality using the P3 as a psychophysiological correlate of attentional allocation. PLoS 7: 50339

9. Hoppenbrouwers, Sylco S, Stigchel SAD, Slotboom J, Dalmaijer ES, et al. (2015) Disentangling attentional deficits in psychopathy using visual search: Failures in the use of contextual information. Personality and Individual Differences 86: 132-138.

10. Seara-Cardoso A, Viding E, (2015) Functional Neuroscience of Psychopathic Personality in Adults. J Pers 83: 723-737.

11. Patrick CJ, Drislane LE, Strickland C (2012) Conceptualizing psychopathy in Triarchic terms: Implications for treatment. Int J Foren Ment Healt 11: 253-266.

12. Baskin-Sommers AR, Curtin JJ, Newman JP (2015) Altering the cognitiveaffective dysfunctions of psychopathic and externalizing offender subtypes with cognitive remediation. Clinical Psychological Science 3: 45-57.

13. Bechara A, Damasio AR, Damasio H, Anderson SW (1994) Insensitivity to future consequences following damage to human prefrontal cortex. Cognition 50: 7-15.

14. Brazil IA (2013) Change doesn't come easy: dynamics of adaptive behaviour in psychopathy. Nijmegen: Donders series.

15. Bettison TM, Mahmut MK, Stevenson RJ (2013) The relationship between psychopathy and olfactory tasks sensitive to orbitofrontal cortex function in a non-criminal student sample. Chemosensory Perception 6: 198-210.

16. van Honk J, Hermans EJ, Putman P, Montagne B, Schutter DJ (2002) Defective somatic markers in sub-clinical psychopathy. Neuroreport 13: 1025-1027.

17. Dean AC, Altstein LL, Berman ME, Constans JI, Sugar CA, et al. (2013) Secondary Psychopathy, but not Primary Psychopathy, is Associated with Risky Decision-Making in Noninstitutionalized Young Adults. Pers Individ Dif 54: 272-277.

18. Morgan JE, Gray NS, Snowden RJ (2011) The relationship between psychopathy and impulsivity: A multi-impulsivity measurement approach. Personality and Individual Differences 51: 429-434.

19. Mahmut MK, Homewood J, Stevenson RJ (2008) The characteristics of noncriminals with high psychopathy traits: Are they similar to criminal psychopaths? Journal of Research in Personality 42: 679-692.

20. Vassileva J, Petkova P, Georgiev S, Martin EM, Tersiyski R, et al. (2007) Impaired decision-making in psychopathic heroin addicts. Drug Alcohol Depend 86: 287-289.

21. Bass SLS, Nussbaum D (2010) Decision making and aggression in forensic psychiatric inpatients. Criminal Justice and Behaviour 37: 365-383.

22. Beszterczey S, Nestor PG, Shirai A, Harding S (2013) Neuropsychology of decision making and psychopathy in high-risk ex-offenders. Neuropsychology 27: 491-497.

23. Mitchell DG, Colledge E, Leonard A, Blair RJ (2002) Risky decisions and response reversal: is there evidence of orbitofrontal cortex dysfunction in psychopathic individuals? Neuropsychologia 40: 2013-22.

24. Baker LA, Tuvblad C, Wang P, Gomez K, Bezdjian S, et al. (2013) The Southern California Twin Register at the University of Southern California: III. Twin Res Hum Genet 16: 336-343.

25. Blair RJ, Colledge E, Mitchell DGV (2001) Somatic markers and response reversal: Is there orbitofrontal cortex dysfunction in boys with psychopathic tendencies? Journal of Abnormal Child Psychology 29: 499-511.

26. Schmitt WA, Brinkley CA, Newman JP (1999) Testing Damasio's somatic marker hypothesis with psychopathic individuals: risk takers or risk averse? J Abnorm Psychol 108: 538-543.

27. Lösel F, Schmucker M (2004) Psychopathy, risk taking, and attention: a differentiated test of the somatic marker hypothesis. J Abnorm Psychol 113: 522-529.

28. Hughes MA (2005) Psychopathic personality traits and lowa Gambling Task performance in incarcerated offenders. Psychiatry, Psychology and Law 22: 134-144.

29. Mol B, Van Den Bos P, Derks Y, Egger J (2009) Executive functioning and the two-factor model of psychopathy: no differential relation? Int J Neurosci 119: 124-140.

30. Prehn K (2013) Neural correlates of risk taking in violent criminal offenders characterized by emotional hypo- and hyper-reactivity. Social Neuroscience 8 : 136-147.

31. Jones AP, Laurens KR, Herba CM, Barker GJ, Viding E (2009) Amygdala hypoactivity to fearful faces in boys with conduct problems and callousunemotional traits. Am J Psychiatry 166: 95-102.

32. Gupta R, Koscik TR, Bechara A, Tranel D (2011) The amygdala and decisionmaking. Neuropsychologia 49: 760-766.

33. Patrick CJ, Edens JF, Poythress NG, Lilienfeld SO, Benning SD (2006) Construct validity of the psychopathic personality inventory two-factor model with offenders. Psychol Assess 18: 204-208.

34. Miller JD, Lynam DR (2012) An examination of the Psychopathic Personality Inventory's nomological network: A meta-analytic review. Personality Disorders: Theory, Research, and Treatment 3: 305-326.

35. Buelow MT, Suhr JA (2009) Construct validity of the lowa Gambling Task. Neuropsychol Rev 19: 102-114. 
Citation: Kuin NC, Masthoff EDM (2016) Investigating the Relationship between Psychopathic Personality Traits and Decision Making Deficits in a Prison Population. J Foren Psy 1: 104. doi: 10.4172/2475-319X.1000104

36. Brand M (2007) Decisions under ambiguity and decisions under risk: Correlations with executive functions and comparisons of two different gambling tasks with implicit and explicit rules. Journal of Clinical and Experimental Neuropsychology 29: 86-99.

37. Schmittmann VD, Visser I, Raijmakers ME (2006) Multiple learning modes in the development of performance on a rule-based category-learning task. Neuropsychologia 44: 2079-2091.

38. Bouma A, Handboek neuropsychologische diagnostiek: tweede herziene druk. 2012, Amsterdam: Pearson Assessment and Information BV.

39. Partington JE, Leiter RG (1949) Partington's Pathway Test. The Psychological Service Center Bulletin 168: 111-117.

40. Raven JC, Court JH, Raven J, Raven (2000) Manual: section 3. Standard Progressive Matrices, San Antoni, TX: Pearson Assessment and Information.

41. Miranda R Jr, MacKillop J, Meyerson LA, Justus A, Lovallo WR (2009) Influence of antisocial and psychopathic traits on decision-making biases in alcoholics. Alcohol Clin Exp Res 33: 817-825.

42. Gignac GE (2009) Partial confirmatory factor analysis: described and illustrated on the NEO-PI-R. J Pers Assess 91: 40-47.

43. Yechiam E (2005) Using cognitive models to map relations between neuropsychological disorders and human decision-making deficits. Psychological Science 16: 973-978.

44. Ahn WY, Busemeyer JR, Wagenmakers EJ, Stout JC (2008) Comparison of decision learning models using the generalization criterion method. Cogn Sci 32: 1376-1402.

45. Lev D, Hershkovitz E, Yechiam E (2008) Decision making and personality in traffic offenders: a study of Israeli drivers. Accid Anal Prev 40: 223-230.

46. Yechiam E, Kanz JE, Bechara A, Stout JC, Busemeyer JR, et al. (2008) Neurocognitive deficits related to poor decision making in people behind bars. Psychon Bull Rev 15: 44-51.

47. Morgan A, Lilienfeld S (2000) A meta-analytic review of the relation between antisocial behaviour and neuropsychological measures of executive function. Clinical Psychology Review 20: 113-156.
48. Kuin N, Masthoff E, Kramer M, Scherder E (2015) The role of risky decisionmaking in aggression: A systematic review. Aggression and Violent Behaviour 25: $159-172$.

49. Braams BR, van Leijenhorst L, Crone EA (2014) Risks, rewards, and the developing brain in childhood and adolescence, in The neuroscience of risky decision making, VF Reyna and V Zayas, Editors. American Psychological Association: Washington, DC, US pp: 73-91.

50. Fein G, McGillivray S, Finn P (2007) Older adults make less advantageous decisions than younger adults: Cognitive and psychological correlates. Journal of the International Neuropsychological Society 13: 480-489.

51. Samanez-Larkin GR, Knutson B (2014) Reward processing and risky decision making in the aging brain, in The neuroscience of risky decision making, VF Reyna and V Zayas, Editors. American Psychological Association: Washington, DC, US pp: 123-142.

52. Verdejo-García A, Bechara A (2009) A somatic marker theory of addiction Neuropharmacology 56: 48-62.

53. Fein G, Klein L, Finn $P$ (2004) Impairment on a simulated gambling task in long-term abstinent alcoholics. Alcoholism: Clinical and Experimental Research 28: $1487-1491$.

54. Fein G, Landman B, Tran H, McGillivray S, Finn P, et al. (2006) Brain atrophy in long-term abstinent alcoholics who demonstrate impairment on a simulated gambling task. Neuroimage 32: 1465-1471.

55. Hare RD (2003) Manual for the Revised Psychopathy Checklist (2nd edn.) Toronto, ON, Canada: Multi-Health Systems.

56. Ray JV (2013) The relation between self-reported psychopathic traits and distorted response styles: A meta-analytic review. Personality Disorders: Theory, Research, and Treatment 4: 1-14.

57. Miller JD, Jones SE, Lynam DR (2011) Psychopathic traits from the perspective of self and informant reports: is there evidence for a lack of insight? J Abnorm Psychol 120: 758-764.

58. Verhage $F$ (1964) Intelligence and age. Research at Dutch from twelve to seventy-seven years. Assen, Netherlands: Van Gorcum. 